\title{
Ocular complications in patients with leprosy in Karigiri, South India
}

\author{
HER HSIN TSAI* \& N SURYAWANSHI \\ Schieffelin Leprosy Research and Training Centre, Karigiri, South \\ India
}

Accepted for publication 24 September 1984

\begin{abstract}
Summary The examination of 143 leprosy patients revealed that 91 had ocular lesions attributable to leprosy and of these 13 were blind. The commonest lesion was madarosis and the commonest cause of blindness was chronic iritis $(31 \%$ of all blind patients). Lagophthalmos remains an important condition and found in $25 \%$ of patients while corneal lesions account for a large number of ocular problems in leprosy (exposure keratitis $31 \%$, interstitial keratitis $8 \%$ ). Most affected is the 40-60 year, age group and most of the affected patients had long-term disease. Lepromatous patients were also encountered more frequently $(70 \%)$ among the involved patients. A large number of patients also suffered from gross deformities $(53 \%)$ and even more so amongst the blind $(77 \%)$. This study does point out the importance of careful and regular examination of the eyes of leprosy patients by all involved with the care of these unfortunate people.
\end{abstract}

\section{Introduction}

As early as 1873 , Hansen and Bull drew attention to the high incidence of ocular complications in leprosy in their book The leprous disease of the eye where they commented that there is no disease which so frequently gives rise to disorders of the eye as leprosy does. ${ }^{1}$ In spite of this early awareness there is still considerable ignorance of many aspects of the problem. Good studies of the subject are few and far between. Several prevalence surveys have been carried out but there is still no standard method of classifying the lesions and this makes their comparison difficult.

The incidence of ocular leprosy is known to vary according to climate, sex, race, type of leprosy and skin pigmentation. One study ${ }^{2}$ has demonstrated a prevalence in Malaysia of $16.3 \%$ while another has shown that $96 \%$ had ocular manifestations in Panama, ${ }^{3}$ both studies being amongst institutionalized patients.

* Correspondence: Dermatology Unit, Ward 29, Royal Infirmary, Foresterhill, Aberdeen, UK, AB9 2ZB. 
Studies in India where leprosy is so common are surprisingly few in number. The following list is an exhaustive survey of the literature available on the prevalence of ocular complications in different parts of India:

\begin{tabular}{llcl}
\multicolumn{1}{c}{ Author } & \multicolumn{1}{c}{ State } & $\%$ with eye lesions & Type of study \\
Neve $(1900)^{4}$ & Kashmir & 25 & Institutional \\
Kirwan $(1928)^{5}$ & Bengal & 20 & Institutional \\
Balakrishnan $(1966)^{6}$ & Tamil Nadu & 46 & Institutional \\
Ebenezer $(1968)^{7}$ & Tamil Nadu & 11 & Retrospective \\
Saxena $(1971)^{8}$ & Madhya Pradesh & 70 & Institutional \\
Dutta $(1972)^{9}$ & Assam & 80 & Institutional \\
Sehgal $(1976)^{10}$ & Goa & 25 & Out-patients \\
Acharya $(1978)^{11}$ & Various & $11 \cdot 3$ & Hospital \\
Reddy $(1981)^{12}$ & Andhra Pradesh & $5 \cdot 1$ & Field
\end{tabular}

Many of the above studies are based on clinical data collected in practice rather than planned organized surveys. Hence they vary considerably in quality. Almost all the studies are on institutionalized patients and do not reflect the leprosy patient population as a whole. The only field study was done by Reddy $e t$ al. Some of the studies list as few as 4 types of ocular lesions while others list more than 20. There is also marked variation in the classification of lesions and there is no general agreement as to whether certain lesions (e.g. cataracts) are secondary to leprotic involvement or not. The numbers of each study are also very variable. Some are based on surprisingly few patients (e.g. Dutta, 45; Saxena, 43) while others are more substantial (e.g. Acharya, 309).

\section{Methods and subjects}

The Schieffelin Leprosy Research and Training Centre in Karigiri, Tamil Nadu consists of a referral hospital of 180 beds. The leprosy control area of Gudiathum Taluk is an area of 1822 square kilometres with a population of 530,000.

The prevalence of leprosy was 26 per 1000 in 1965 but came down to 19 per 1000 in 1981. The total number of patients in this area was 9950 (1981) of which 6099 were registered in the control area. Because of population movements and the common practice of patients to seek help away from home for social reasons, many of the patients at the hospital, both in-patients and out-patients, come from neighbouring districts.

Patients attending the out-patient clinic at the Eye Department, over a period of 8 weeks, were examined for ocular complications. Their name, age, sex, hospital number, classification of disease and duration of disease were systematically documented. The Ridley-Jopling 5-group system of classification based on immunological studies was used in this survey. ${ }^{13}$ Classification was done clinically, except where histological examination of skin or nerve biopsies were indicated. Each patient was examined in the following way. Vision was tested 
using Snellen charts with conventional or Tamil letters and the E-chart for those unable to read. Patients were tested for digital discrimination, hand movement or light perception if their vision was poorer than 6/60. Vision was recorded in the conventional way after refractive error was corrected, since refractive error is unrelated to leprosy. Presence of brow and eyelid lesions were also noted and facial palsy with lagophthalmos was tested for. In all cases, the eye was examined with a focussing torch and pupillary reflexes noted. The cornea, anterior chamber and iris were examined with a binocular loupe. Corneal sensitivity was tested with a wisp of cotton. The majority of patients were examined biomicroscopically with a binocular slit lamp. Fluorescein strips were used to detect active ulcers, tonometry performed with a Schiötz tonometer and fundoscopy by an ophthalmoscope after instilling a midriatic.

Physical deformities (disabilities) were also noted and classified according to the WHO international classification: grade I, anaesthesia alone; grade II, correctable deformity; and grade III, uncorrectable deformity.

Eye lesions not related to leprosy were excluded from the study and they include senile cataracts, primary glaucoma, pterygiums, Bitot's spots and refractive errors.

\section{Results}

A total of 143 patients were examined as detailed above and of this number, 91 patients had ocular complications attributable to leprosy. Senile cataracts, foreign bodies and other eye conditions not related to leprosy made up the 52 patients not included in this study.

Of the 91 patients with ocular lesions 75 were males while 16 were females $(82 \%$ males, $18 \%$ females $)$. This gives a $5: 1$ male to female ratio, which. is spuriously high because of the 143 random patients examined: 104 were males compared to 39 females. Furthermore, there is a male predominance over female in the prevalence of leprosy in this area being $1.5 \times$ greater and this predominance is even greater amongst sufferers of lepromatous leprosy $(2 \cdot 6 \times)$. Sex specific prevalence however does give a higher male involvement of $72 \%$ compared to $41 \%$ amongst females.

There was a wide range of age groups affected from the age of 9 years to over 60 . Those of the fifth decade were most affected (31 patients). The type of leprosy according to the Ridley-Jopling classification of the 91 patients showed the following distribution: 64 were lepromatous (LL), 11 were borderline lepromatous (BL), 13 were borderline tuberculoid (BT), 1 tuberculoid (TT), and 2 Indeterminate (I).

Of the patients with eye involvement, 28 had grade I deformity, 15 had grade II deformity and 48 had grade III deformity. If the definition of blindness is taken to mean a vision of less than $3 / 60$ in the better eye, there are 13 blind patients in the 
series. The cause of their blindness may be multiple. The main lesion in the 13 patients responsible for the blindness are: 4 with chronic plastic iridocyclitis; 1 with bilateral facial paralysis; 2 with interstitial keratitis; 1 from healed corneal ulcers; 2 bilateral cataracts and 3 with old corneal opacities of unknown cause (forgotten). Of this number, 10 had grade III deformities. A summary of the distribution of individual lesions of the eye caused by leprosy is listed in Table 1.

\section{Discussion}

It must be emphasized that this study suffers from the same failures as the clinical observations of other authors based on hospital populations. It thus gives no indication of the actual prevalence of ocular lesions in this district. The only extensive field study is by Redd $y^{12}$ et al., who in Andhra Pradesh shows (4.72\%) of LL and $(1.15 \%)$ of non-LL patients had ocular lesions. However, their study is largely dependent on paramedical workers for the detection of ocular lesions. One study ${ }^{14}$ had noted that paramedical workers are quite incompetent in this respect in a field test. While most could identify lagophthalmos, they were unable to detect cataracts, scleritis, episcleritis, iridocyclitis and ectropion. This, together with the fact that many lesions are silent, may mean that the figure derived by Reddy is far too conservative. A more realistic figure is likely to be $10-20 \%$. However, prevalence of ocular leprosy does vary from place to place and clearly there is a need to make further studies along standardized lines.

Most authors have demonstrated a male predominance of ocular leprosy over females. Das ${ }^{15}$ found $85 \%$ males to $15 \%$ females, Acharya $1170 \%$ males to $30 \%$ females. This is partly due to the higher prevalence of leprosy amongst males as noted earlier. Males were also noted to be $1.8 \times$ more likely to develop ocular lesions in this series.

There have been no previous studies on the disabilities or deformities that patients with ocular lesions had. This study shows a high incidence $(53 \%)$ of grade III deformities, i.e. incorrectable deformities which include loss of fingers, amputations and gross deformities of the hands. This does illustrate how tragic loss of vision, on top of these deformities can be. Even in the $31 \%$ with anaesthesia alone, many have glove and stocking anaesthesia which means loss of a great deal of the sense of touch and pain.

Madarosis remains the commonest lesion, $59 \%$ of the present series is a shade higher than Acharya's study but almost twice the other two. Ectropion, found in $9 \%$ of the patients is of similar magnitude as in the other figures. It was almost always associated with lagophthalmos, although senility may be a contributory factor. Entropion was found in a higher number of patients than previously documented and was usually associated with trichiasis.

Chronic conjunctivitis covers a rather loose group of conditions which include mainly exposure conjunctivitis from the loss of blink reflex. It is usually 
Table 1. Ocular lesions in leprosy

\begin{tabular}{|c|c|c|c|}
\hline $\begin{array}{l}\text { Lesion } \\
\text { Site }\end{array}$ & Type & $\begin{array}{l}\text { No. of } \\
\text { patients }\end{array}$ & s $\%$ \\
\hline \multirow[t]{2}{*}{ Eyebrows } & Madarosis: mild & $15)$ & \\
\hline & $\begin{array}{l}\text { moderate } \\
\text { severe }\end{array}$ & $\left.\begin{array}{l}20 \\
19\end{array}\right\} 545$ & 59 \\
\hline \multirow[t]{6}{*}{ Lids } & Madarosis & 27 & 30 \\
\hline & Nodules & 1 & 1 \\
\hline & Lagophthalmos: mild & $7)$ & \\
\hline & $\begin{array}{l}\text { moderate } \\
\text { severe }\end{array}$ & $\left.\begin{array}{r}11 \\
5\end{array}\right\} 23$ & 25 \\
\hline & Ectropion & 8 & 9 \\
\hline & Entropion/trichiasis & 8 & 9 \\
\hline Conjunctiva & Exposure conjunctivitis & 10 & 11 \\
\hline \multirow[t]{9}{*}{ Corneal } & Corneal anaesthesia & 22 & 24 \\
\hline & Corneal ulcer: mild & 4) & \\
\hline & $\begin{array}{l}\text { moderate } \\
\text { severe }\end{array}$ & $\left.\begin{array}{l}6 \\
0\end{array}\right\} 10$ & 11 \\
\hline & Exposure keratitis: mild & 9) & \\
\hline & $\begin{array}{l}\text { moderate } \\
\text { severe }\end{array}$ & $\left.\begin{array}{r}8 \\
11\end{array}\right\} 28$ & 31 \\
\hline & Pannus & 7 & 8 \\
\hline & Superficial punctuate keratitis & 5 & 5 \\
\hline & Interstitial keratitis & 7 & 8 \\
\hline & Nodules & 1 & 1 \\
\hline Episclera & Episcleritis & 5 & 5 \\
\hline \multirow[t]{2}{*}{ Sclera } & Scleritis & 2 & 2 \\
\hline & Scleral nodules & 1 & 1 \\
\hline \multirow[t]{12}{*}{ Uveal tract } & Acute iridocyclitis: mild & $5)$ & \\
\hline & $\begin{array}{l}\text { moderate } \\
\text { severe }\end{array}$ & $\left.\begin{array}{l}2 \\
3\end{array}\right\} 10$ & 11 \\
\hline & Chronic iritis & 14 & 15 \\
\hline & Irregular pupils & 32 & 35 \\
\hline & $\begin{array}{c}\text { Pupillary reflex: sluggish } \\
\text { absent }\end{array}$ & $\left.\begin{array}{l}17 \\
13\end{array}\right\} 30$ & 33 \\
\hline & Anisocoria & 22 & 24 \\
\hline & Iris atrophy & 17 & 19 \\
\hline & Polycoria & 1 & 1 \\
\hline & Iris prolapse & 7 & 8 \\
\hline & Anterior synechiae & 4 & 4 \\
\hline & Posterior synechiae & 17 & 19 \\
\hline & Iris pearls & 1 & 1 \\
\hline Secondary glaucoma & & 3 & 3 \\
\hline
\end{tabular}


associated with facial palsy and seen in $11 \%$ of cases and a similar figure is quoted by Reddy.

Corneal anaesthesia was seen in $24 \%$ of patients. However, it must be noted that not all cases of anaesthesia are a direct complication of bacillary invasion but may be secondary to healed corneal ulceration with the formation of a dense leucoma. Acharya found $59 \%$ with such a defect and Reddy $32 \%$. Krassai had reported few cases of anaesthesia in his study. ${ }^{16}$ The reason for this discrepancy is not immediately clear.

Superficial punctuate keratitis, found in $5 \%$ of the cases compares with similar figures $(5 \%, 4 \%, 3 \%)$ by other authors. This does show that it is a relatively unusual condition although pathognomonic of leprosy and also transient and often asymptomatic.

Exposure keratitis was found in a large number of patients, $31 \%$ compared with only $3 \%$ reported by Reddy, although Acharya reported $24 \%$. It is always associated with lagophthalmos or corneal anaesthesia with loss of blink reflex. Of the 23 cases of lagophthalmos, 10 also had corneal anaesthesia out of a total of 22 with corneal anaesthesia.

Thus, out of 22 patients with corneal anaesthesia, 10 had lagophthalmos $(45.5 \%)$ while out of the 69 patients without corneal anaesthesia, 13 had lagophthalmos $(18 \cdot 8 \%)$. This demonstrated that lagophthalmos was significantly more frequent among patients with corneal anaesthesia. $\left(P<0.05, \chi^{2}\right.$ test $)$. This finding is consistent with Anita's theory of the pathogenesis of facial palsy. ${ }^{17}$

Scleritis and episcleritis remain as relatively rare conditions, found in $2 \%$ and $5 \%$ respectively. Only 1 case of episcleral nodule was noted. Acute iridocyclitis was found in a larger proportion ( $11 \%$ ) of patients than previously reported $(3 \%$, $3 \%, 1 \%$ ) but half of the cases were very mild.

Chronic iritis (chronic plastic iridocyclitis) was found in 15\% of patients. Similar figures have been reported by Das and Reddy. This study also confirmed Choyce's observation that chronic iritis was the most common cause of blindness in leprosy. In this study it accounted for $31 \%$ of the blind patients. Much work has been done by ffytche ${ }^{18}$ in an attempt to unravel the pathogenesis of this condition. He concluded that chronic iritis, unlike acute iritis, is not due to immune complex deposition but due to paralytic atrophy of the iris caused by lepromatous involvement of nerve supply to the iris manifesting clinically as iris pearls.

No case of posterior segment involvement was diagnosed. Reddy also found no involvement, while Acharya found only 2 patients with choroidal lesions in his large series of 309 patients. This does demonstrate the rarity of posterior segment involvement and possibly early effective treatment of multibacillary disease may well arrest its appearance.

\section{Acknowledgments}

I am extremely grateful to Dr J Berkeley, Dr E P Fritschi, the Director of 
Schieffelin Leprosy Research and Training Centre, Karigiri, Dr Christian of the Department of Epidemiology and Mr A Waudby of The Leprosy Mission International, London without whom this study would not have been possible. This work was sponsored by The Leprosy Mission International, London.

\section{References}

1 ffytche TJ. The eye and leprosy. Lepr Rer 1981; 52: 111-19.

2 Hobbs HE, Choyce DP. The blinding lesions of Leprosy. Lepr Rev, 1971; 42: 131-7.

${ }^{3}$ Harrel JD. Ocular leprosy in the canal zone. Int J Lepr, 1977; 45: 56-60.

${ }^{4}$ Neve A. Notes on Ocular Leprosy. Brit Med J 1900; 1: 1153.

${ }^{5}$ Kirwan EWO. The Eye in Leprosy. Trans Roy Soc Trop Med Hyg, 1948; $41: 583$.

${ }^{6}$ Balakrishnan E. Survey of ocular complications in Lepromatous Leprosy. J All India Ophrthal Soc, 1966; 14: 214-16.

7 Ebenezer R. Eye Lesions in Leprosy. Karigiri Review, 1968; 2: 68-77.

${ }^{*}$ Saxena RC, Dwinvedi MP. Ocular Manifestations in Hansens Disease. Lepr India, 1971; 43: $7-10$.

${ }^{9}$ Dutta LC, Das NC, Chatterjee BC, Bujarbania DN. Ocular Lesions in Leprosy. J Indian Med Assn 1973; 61: 385-8.

10 Sehgal VN, Aggarwal DP, Sehgal N. Ocular Leprosy. Indiun J Med Res, 1976; 64: 1600-6.

11 Acharya BP. Ocular Involvement in Leprosy: A study of the Mining Areas in India. Indicun J Ophthal, 1978; 11: 21.

12 Reddy SC, Raju BD, Achary NRSB. Survey of Eye Complications in Leprosy in Prakasam District (Andhra Pradesh). Lepr India, 1981; 53: 231-9.

1. Ridley DS, Jopling WH. Classification of Leprosy According to Immunity. Int J Leepr, 1966; 34: 255-73.

14 Verma N. An Assessment of the Usefulness and Acceptability of Eye Shields under Field Conditions. Lepr Rev 1981; 52: 141.

15 Das R, Goswami A, Mitra AK, Roy IS. Ocular Complications in Leprosy. J Indian Med Assn 1980; 78: 5-8.

16 Krassai A. Corneal Sensitivity in Lepromatous Leprosy. Int J Lepr 1970; 38: 422-7.

17 Antia NH, Devikar SC, Dastur DK. Facial Nerve in Leprosy. Int J Lepr 1966; 34: 103-17.

18 ffytche TJ. Role of Iris Change as a Cause of Blindness in Leprosy. Brit J Ophthal 1981; 65: $231-9$. 